\title{
THE EFFECT OF ART TRAINING UPON DRAWING BY CHILDREN IN A MULTI-CULTURAL SETTING
}

\section{Alan Richards}

The American society is frequently called "the melting pot" because its composition is a unique blend of people from different cultures. In the past, people from all over the world came to America in search of the opportunities which were not available in other societies. Over the years these people became Americanized, adopting the customs and mores of what is referred to as the "American Culture." Presently, there is a new surge of people from diverse cultural persuasions entering the United States. According to Lovano-Kerr (1985), the non-Englishspeaking population in the United States is expected to increase from the current 30 million to approximately 39.5 million in the year 2000 . This increase in cultural diversity is reflected among children attending the public schools. Art educators are particularly concerned because the current pedagogical methodologies are inadequate to grapple with this situation. Cross-cultural studies can provide useful information that may lead to the development of methodologies that are successful in teaching art to children in a multi-cultural group.

Studies in art education support the position that perceptual training improves drawings by children in a single-cultural group. It is not known if perceptual training can improve drawings by children in a multi-cultural setting. Therefore, this investigation will attempt to find out if art training can affect changes in drawings by children in a multi-cultural setting. The literature for this investigation was selected from three major areas: theories about children's drawings, cross-cultural studies in drawings, and studies in drawing strategies.

There have been different theories about how and why children draw the way they do. Arnheim (1974) has been frequently cited for his theories about how children draw. One of his most widely recognized theories is the "Intellectualistic Theory." In this theory, Arnheim 
stated that children limit themselves to representing the overall quality of objects because they draw what they know rather than what they see. Another theory, by Kellogg (1969), is that children portray symbols in their drawings that correspond to their level of artistic development. These theories may have addressed the issue of "why children draw the way they do," but they have not explained why children's drawings differ from culture to culture.

Wadsworth (1984) may have addressed the issue of differences in drawings by children from different cultures when he spoke about the factors responsible for constructing knowledge. He suggested that there were four factors responsible for the development of mental structures. These factors were: maturation, physical experiences, social interaction, and equilibration. According to Wadsworth's theory, children from different cultures differ in their rate of maturation, social interaction, and physical experiences, so their drawings tend to portray those differences.

According to Wilson and Wilson (1982), children build reality or knowledge through the search for information about the environment in which they live. They then utilize this information in their drawings to construct and/or invent models of the world or models of reality. Wilson and Wilson stated that children's drawings are combined with innate-determined features and features that are experiences in the culture. For example, American children's drawings portrayed space rockets and other space vehicles, monsters and dinosaurs. These images were a part of the fabric of the American culture. In some cultures, it would be difficult to expect children's drawings to portray these images. Space vehicles, dinosaurs, Mickey Mouse, and anthropomorphic creatures were not a part of those cultures, stated Wilson and Wilson.

The belief that visual symbols in children's drawings were universal was rejected by Wilson and Wilson. They stated that because of innate preferences for certain types of visual order, children from all over the world shared a predisposition to arrange lines and shapes in a certain way. This led to certain similarities among the drawings by children regardless of cultural background. But Wilson and Wilson also supported 
the idea that children's drawings were different because of cultural influences.

Differences in children's drawings were also supported by Alland's (1983) empirical investigation of how children from six different cultures drew the human figure and how they used limited colors. Children from Bali, France, Japan, Ponape, Taiwan, and the United States of America participated in the study. Results indicated that Japanese children's drawings of the human figure were the most sophisticated of those groups participating. According to Alland, this finding reflected the quality and quantity of art training available to Japanese children. Children from Bali and Ponape produced the least sophisticated drawings of the human figure. In Bali and Ponape, drawing the human figure was extremely unusual among school children. Alland concluded that culture played an important role in the development of children's drawing style and at a very early age.

In another cross-ultural study, Brittain (1985) analyzed children's drawings from Queensland, Australia, and New York, United States of America. Brittain believed that children between four and five years of age from diverse background would show similarities in their early representations. "Eating" was the topic discussed with subjects prior to the drawing experiment. Children from New York drew interior scenes, automobiles, picnic tables, television sets, and stoves. On the other hand, children from Queensland drew outdoor fires, palm trees, kangaroos, alligators, and houses on stilts. It was also observed that children from New York portrayed themselves eating inside a house, while children from Queensland portrayed themselves outside of a house. According to Brittain, drawings by children from Queensland indicated that they were from a culture different from New York.

Several studies in art education have supported the theory that perceptual training does improve children's drawings. In one study, Rennels (1969) tried to identify methods that would assist the Negro child to discover and to respond to sensory experiences. The child's ability in spatial perception was developed and studied through perspec- 
tive drawing and photographs. It was believed that concrete and motoric experiences would help the Negro child acquire basic skills in discovering and responding to sensory stimuli. Two methods of instruction were used in this study: analytic and synthetic. Rennels concluded that the analytic method of instruction was superior to the synthetic method of instruction. However, he mentioned that the success of the analytic method was due to interest arousal through the use and novelty of the Polaroid camera. Rennels also stated that from discussions and the use of a camera, children learned a different manner of responding to visual stimuli.

Burn (1975) investigated the effect of tracing photographs or contour drawings in combination with practice in visually discriminating foreground, middleground, and background, and the effect of how cues were responsible for illusion of three-dimensional picture plane. Results from this investigation indicated that both photographic and contour-line tracing were significant in spatial visualization tasks.

Another study was done by Lansing (1984), who stated that a successful representation cannot be made if the delineator does not possess a mental representation of the object being drawn. He investigated the effect of drawing upon the development of mental representation in children. Children were exposed to five different drawing experiences in which they were asked to observe and draw a two-dimensional abstract object. From the result, it was observed that a more accurate and fully developed mental image was produced when children received instruction, drew objects repeatedly, and drew with pointed pencils and brushes.

To conclude, the literature reviewed here supports three basic positions regarding the differences found in children's drawings and the art training influence on their drawings: (1) culture does influence children's drawings style, spatial ability, the rate at which developmental characteristics appear, pictorial characteristics in their landscape drawings, values, use of colors, and representation of three-dimensional forms; (2) instruction and practice improve drawings by children from a single-cultural population; and (3) children from different cultures differ in their rate of maturation, social interaction, and physical experiences so their drawings tend 
to portray these differences. There were no specific references in the literature to art training among children in a multi-cultural setting.

It seems obvious that maturation, physical experiences, and social interaction are the three major factors responsible for cultural differences found in children's drawings. Maturation is closely associated with a biological process in which each individual has to reach an appropriate developmental stage, sometimes determined by chronological age, in order to function effectively at various established physical and intellectual levels. However, biological maturation does not guarantee maturity in specific functions. Maturity in specific functions is determined when maturation is complemented by various types of experiences. For example, if a child is ready mentally and physically to pursue specific art functions and training is not available, then maturity in those functions would not be realized. On the other hand, if training was available, there would be a great possibility that maturity in specific art functions would be realized. To assess the effect of art training upon drawings by children from a multicultural setting, it should be assumed that the children are already matured biologically.

Controlled practice and/or training and instruction can improve accuracy in representational drawings. It seems logical that instruction and practice in drawing would provide the child with specific types of experiences. These experiences contribute tremendously in developing the child's mental images of the object being drawn. The more developed the child's mental images of the object, the more accurate will be the graphical representation. From this logic, children who are trained in specific drawing activities will excel over children who were not trained in similar activities. Therefore, although children may differ in their cultural persuasion, if they receive the appropriate art training, their drawings should improve. It is recommended, however, that empirical research be done to verify this conclusion. 


\section{REFERENCES}

Alland, A. (1983). Playing with forms: Children drew in six cultures. New York: Columbia University.

Arnheim, R. (1974). Art and visual perception: A psychology of the creative eye. Berkeley: University of California.

Brittain, L. (1985). Children's drawings: A comparison of two cultures. Journal of Multi-cultural and Cross-cultural Research in Art Education, 3 (1), 34-42.

Burn, E. (1975). The effect of two tracing treatments upon the representational drawing of sixth-grade students. Illinois State University, Center for the Visual Arts, Normal, IL.

Kellogg, R. (1969). Analyzing children's art. Palo Alto: National Press Docks.

Lansing, K. (1984). The effect of drawing on the development of mental representations: A continuing study. Studies in Art Education, 25 (3), 167-175.

Lovano-Kerr, J. (1985). Cultural diversity and art education: A global perspective. Journal of Multi-cultural and Cross-cultural Research in Art Education, 3 (1), 25, 33.

Rennels, M. (1969). Two methods of teaching spatial tasks to disadvantaged Negroes. Studies in Art Education, 11 (1), 44-51.

Wadsworth, B. (1984). Piaget's theory of cognitive and effective development (3rd ed.). New York: Longman, Inc.

Wilson, M. $\varepsilon$ Wilson, B. (1982). Teaching children to draw: guide for teachers and parents. Englewood Cliffs, NJ: Prentice-Hall. 